\title{
Job descriptions: What they are, are not, and can be
}

\author{
By Barbara DeLon
}

\section{Make the most of your job descriptions}

- efore reading ahead, answer this ques- tion: What does your own job description say? No cheating now. If you can answer this question without searching your files or those of the personnel officer, my guess is that you're still fairly new to your current position or you are one of the small minority who have learned to have this valuable resource. Most of us who have been on the job for a long time lose touch with the job description we analyzed so carefully when we started (assuming we had one at all). The truth is that, in many organizations, job descriptions don't count for much. But it doesn't have to be that way.

The first step to making job descriptions meaningful is deciding that they should be. Once there is a viable system in place, managers and employees should keep job descriptions relevant. And when they are relevant, they are likely to be used.

\section{Capture the focus of the job}

The idea of job descriptions is to capture the focus of the job. In order to do this, managers and employees alike must move away from the historical purposes and limitations of the job description. It is not a contract, nor an all encompassing list of duties or responsibilities. People who think it is all of these things come to expect too much of the document.

The job description should help with staffing, planning and continuity, orientation, training, performance appraisal, compensation (when available), and legal and regulatory requirements.
Historically, job descriptions were submitted by managers who wanted to promote an employee. This is still so in many instances. Many of these documents contain ambiguous statements and very little thought appears to have been given to content or to the possibility of using it for any other purpose.

"Job descriptions should be used for other purposes," says Laurie Charest, associate vicechancellor, human resources, University of North Carolina at Chapel Hill (UNC-CH). "To be useful, a job description should include several elements: a list of the position's major re sponsibilities, other departments that interact with the person in this position on a regular basis, minimum skills required to perform the job, special requirements or working conditions, who supervises this employee and who does this employee supervise? This [is] the minimum information necessary in developing a job announcement or a reclassification description."

Writing job descriptions from scratch, or revitalizing job descriptions that are badly out of touch, requires the effort of management and employees as well as the Human Resources Department. Clearly, employees and their immediate supervisors know the most about the positions they hold; they are the prime sources of information about the responsibilities of and skills needed for each job. However, the information they provide must be put into a clear, consistent format before it will be useful.

If the absence of job descriptions is creating a problem, it is best to devise a simple, brief description format that encompasses the required information. After completion of this process, the supervisor should be asked to sit down with the employee and complete a current description. 
Supervisors should be warned not to include every possible detail of the job. Job descriptions are not a comprehensive, exhaustive list of all the duties and secondary duties an employee may perform in the course of a day or a year. A job description should exist in order to help people work with one another, and too much detail takes away from that goal. A job description must be accurate, but not minutely detailed.

\section{Many uses for job descriptions}

One of the best ways to make sure job descriptions are accurate is to use them. Use them in every way possible including recruitment, job evaluation, mentoring, career counseling, and in other purposes. Inaccuracies are sure to surface and will be corrected in less time. Usage will also give the job description life, making it a meaningful part of the total management of the organization.

"Ask supervisors to look over the job descriptions periodically," says Ann Register, pay-
A job description should exist in order to help people work with one enother, end too much detall tokes eway from that goal. recruiting immediately. You don't first have to spend time trying to determine which aspects of the job are most important. Of course, job descriptions don't replace talking with the recruitment officer, but they do give you a solid place to start. Use them when orienting new employees

The job description can tell an employee why tasks are being done and what your expectations are.

Take a look at your own organization and find the ways in which job descriptions can work for you.

\section{References}

Aft, Lawrence S. Wage and Salary Administration: A Guide to Job Evaluation. Reston, Va.: Reston Publishing Company, Inc., 1985.

Collinsworth, Barbara. "Student workers: Our most important asset." Community and Junior College Libraries 3 (Spring 1985): 9-12.

Dowen, Christopher T. "Developing a compensation system: The roll-personnel representative, Academic Affairs Library, UNC-CH. "It is important to review how the job fits into the bigger picture. This exercise will also reinforce the fact that job descriptions are never really finished documents because in the current work environment, things keep changing."

If a job description is out of line with the work that's being done, find out why. It may be that the employee has been neglecting elements of the job and needs to be guided back to the responsibilities stressed in the job description. More often, the job has simply evolved to fit the changing needs of the organization. In that case, the job description should be revised. If the job descriptions diverge, their credibility is undermined. The people using them will stop, and will create their own version for their own purposes. The result: confusion and conflict.

If you can't do a regular review of the job description, I suggest the following alternative times: when the job changes (in particular, when new technology is introduced), at the time of performance review, reorganization, or when a long-service employee leaves the position.

When you need to replace an employee, having a current job description lets you start experience of the Downers Grove Public Library." Library Trends 30 (Summer 1989): 12742

Elizur, Don. Job Evaluation: A Systematic Approach. Bar Ilan University and The Israel Institute of Applied Social Research. West Mead, England: Gower Publishing Company Limited, 1980.

How to Write Job Descriptions - the Easy Way. Stamford, Conn.: Bureau of Law and Busi ness, Inc., 1982.

Line, Maurice D. "How to demotivatestaff. A brief guide." Library Management 13 (1992): 47.

Parrish, Jenni. "The joys of law library management are without number." Legal Reference Services Quarterly 6 (Fall/Winter 1986): 61-79.

How to Do Pay Equity Job Comparisons. Toronto, Ont.: The Pay EquityCommission, 1989.

Price, Cheryl A. "What professional librarians expect from administrators: One librarian's view. College and Research Libraries 40 (September 1987): 400-12.

Shaughnessy, Thomas W. "Redesigning library jobs." Joumal of the American Society for Information Science 29 (July 1970): 107-90.

Shuman, David. Public Administration in the United States. 2nd. ed. Lexington, Mass.: D.C. Heath, 1993. 


\section{-ACS Publications Landmark Science Series.}

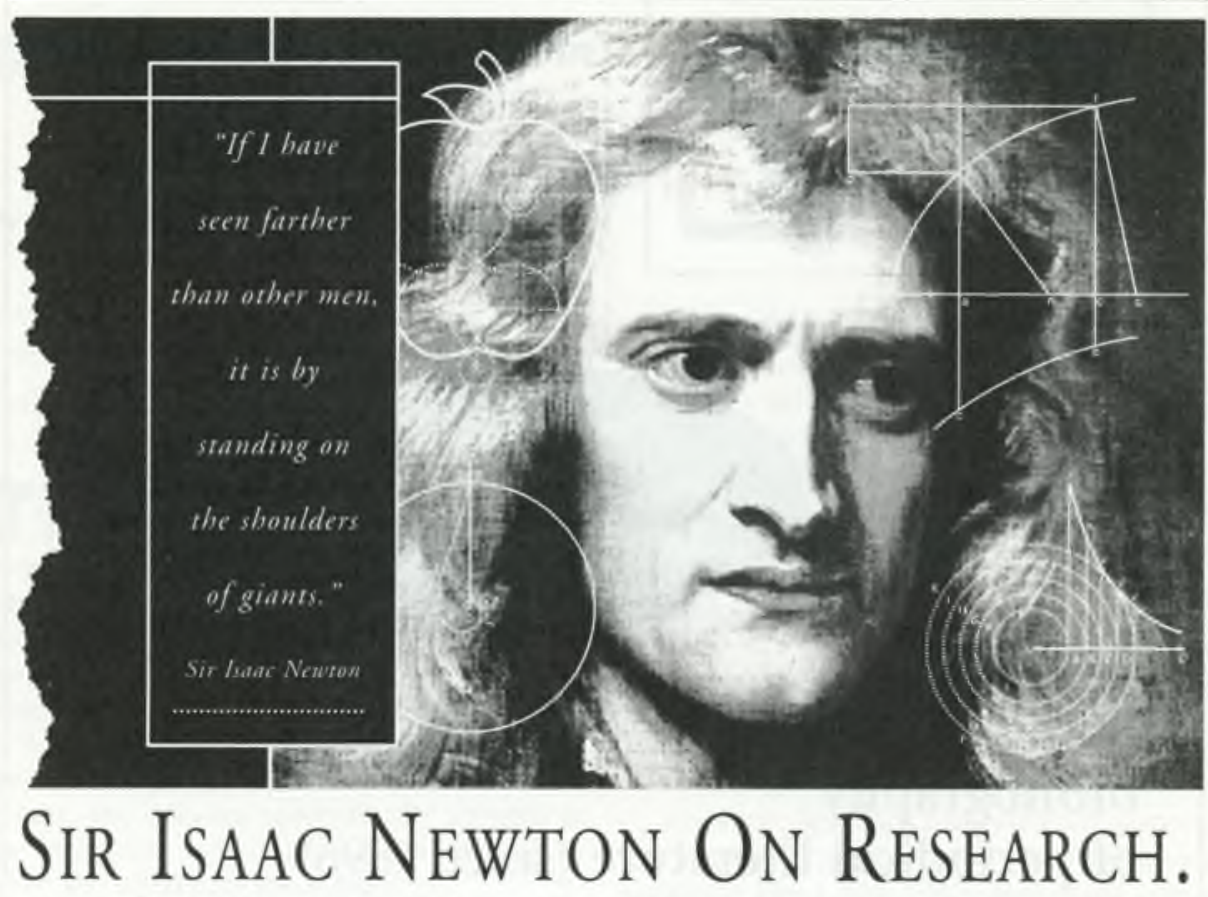

He developed the theory of gravity.

He invented calculus. His concept of time and space defined the known universe for nearly 200 years. A natural philosopher who advanced the fields of optics, physics and chemistry, Sir Isaac Newton saw science as the cumulative achievement of mankind. He understood the value of the published record.

So do we. The American Chemical Society has demonstrated an unparalleled commitment to the quality of scholarship in its scientific journals since 1876. This commitment is clear from our peer review process, among the most stringent in the industry, which in turn attracts increased submissions by eminent authors, a rise of $56 \%$ last year over the number 10 years ago.

Today, science libraries are caught in a riptide of changing demands and increased pressures. We're doing what we can to help-ACS journals cost, on average, about $25 \%$ of the price charged for commercial journals in our discipline.
Yet their quality remains high. Write or fax ACS Publications today, and we'll send you the results of our most recent reader surveys: objective evaluations of ACS journals by chemists. Please include your suggestions about how we can serve you better.

Working together, we'll support new landmarks in scientific achievement by raising the shoulders on which future generations may stand.

\section{ACS IIIPUBLICATIONS}

Essential Resources for the Chemical Sciences 1155 Sisteenth St. NW, Washington, D. C. 20036 USA

Let us hear from you. Fax (202) 872-6005

F A X B A C K CRLN,
Yes, please send me your recent reader surveys.
My suggestions are included on a separate sheet.
Name
Library




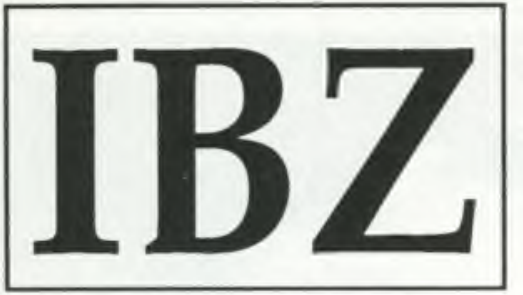

International Bibliography of Periodical Literature covering all fields of knowledge

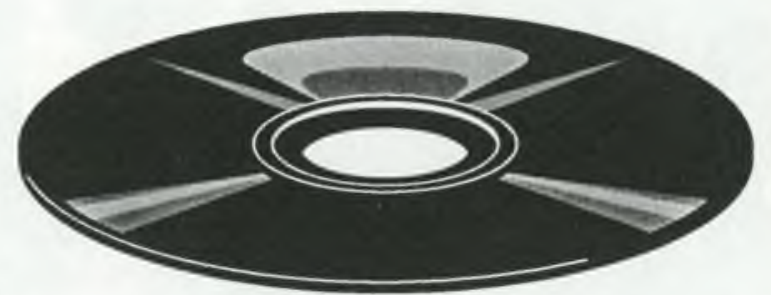

The oldest

European universal

bibliography

of periodical literature (since 1896)

now on

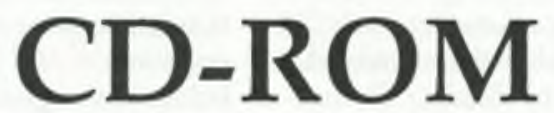

650000 data records (1989-1993) on a single Compact Disc

Please visit our stand for a test at the

\section{ALA-Conference}

June 25-28, 1994

Miami Beach, FL

Convention Center

Location 200

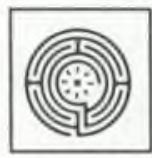

DIETRICH

Zeller publications

D-49009 OSNABRÜCK Germany 